\title{
Split Converter-Fed SRM Drive for Flexible Charging in EV/HEV Applications
}

\author{
Yihua Hu, Member, IEEE, Chun Gan, Student Member, IEEE, Wenping Cao, Senior Member, IEEE, \\ Chushan Li, Member, IEEE, and Stephen Finney
}

\begin{abstract}
Electric vehicles (EVs) and hybrid electric vehicles (HEVs) are the way forward for green transportation and for establishing a low-carbon economy. This paper presents a split converter-fed four-phase switched reluctance motor (SRM) drive to realize flexible integrated charging functions (DC and AC sources). The machine is featured with a central tapped winding node, eight stator slots and six rotor poles (8/6). In the driving mode, the developed topology has the same characteristics as the traditional asymmetric bridge topology but better fault tolerance. The proposed system supports battery energy balance and on-board DC and AC charging. When connecting with an AC power grid, the proposed topology has a merit of the multi-level converter; the charging current control can be achieved by the improved hysteresis control. The energy flow between the two batteries is balanced by the hysteresis control based on their state-of-charge (SoC) conditions. Simulation results in Matlab/Simulink and experiments on a $150 \mathrm{~W}$ prototype SRM validate the effectiveness of the proposed technologies, which may provide a solution to $\mathrm{EV}$ charging issues associated with significant infrastructure requirements.
\end{abstract}

Index Terms-Battery chargers, DC-DC power conversion, electric vehicles, hybrid electric vehicles, integrated chargers, propulsion, switched reluctance motors.

\section{INTRODUCTION}

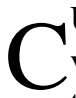
URRENTLY, electric vehicles (EVs) and hybrid electric vehicles (HEVs) represent the future of green transportation and thus are under extensive development across the world [1], [2]. In terms of motor drive topology, high-performance permanent magnet (PM) motors are advantageous but unsustainable for mass production market such as EVs/HEVs because of the scarcity of rare-earth materials they rely on [3]. In contrast, switched reluctance motors (SRMs) are becoming a mature technology and are considered to have commercial potentials in widespread

Manuscript received May 31, 2014; revised January 13, 2015 and February 24, 2015; accepted April 5, 2015.

Copyright (c) 2015 IEEE. Personal use of this material is permitted. However, permission to use this material for any other purposes must be obtained from the IEEE by sending a request to pubs-permissions@ieee.org.

This work was supported by the EPSRC of UK (EP/L00089X/1)

Y. Hu is with the College of Electrical Engineering, Zhejiang University, Hangzhou 310027, China; and is also with the Department of Electronic and Electrical Engineering, University of Strathclyde, Glasgow, U.K.

C. Gan (corresponding author) is with the College of Electrical Engineering, Zhejiang University, Hangzhou 310027, China (e-mail: ganchun.cumt@163.com).

W. Cao is with the School of Electronics, Electrical Engineering and Computer Science, Queen's University Belfast, Belfast, U.K.

C. Li is with the Department of Electric and Electronics Engineering, Ryerson University, Toronto, Canada

S. Finney is with the Department of Electronic and Electrical Engineering, University of Strathclyde, Glasgow, U.K. applications due to their rare earth-free feature and wide-range torque-speed characteristics. SRMs have advantages of robust mechanical structure, low cost, high efficiency and a wide speed range [3]-[12]. However, in order to operate EVs/HEVs in urban environment, a large number of charging stations should be built in a similar manner to gas stations for internal combustion engine (ICE) vehicles. A basic EV/HEV drive structure is shown in Fig. 1. Furthermore, there is also a need to upgrade the existing power grid if a large number of EVs/HEVs are connected to it. Clearly, the infrastructure costs can be significant if we were to replace half of existing ICE cars by electrified ones within 20 years.

To tackle this problem, a current trend is to develop high power on-board chargers to overcome range limitations [13]-[27]. This is achieved by improving converter technologies, integrating the charger with the converter, or integrating the charger with the drive motor. The first route is shown in the example in [21], which proposes a three-port DC-DC converter with power factor correction. The second route is presented in [22] which integrates a bi-directional AC-DC charger with a DC-DC converter. In this case, the charging system can control energy flow between the high voltage bus and the battery pack but its circuitry is complicated and the available power flow modes are limited. The third route is described in [23]-[27] which integrate the on-board charger with the drive motor, so as to utilize the machine windings for charging purposes. A $20 \mathrm{~kW}$ PM split-phase motor drive is specially designed and its traction/charging modes are controlled by a switch based relay [23], [26], but the motor suffers from low charging power $(<3 \mathrm{~kW})$ and high harmonic contents in the back electromotive force (EMF). The same method for a split-phase induction machine was developed in [27] to provide three grid-connected nodes, which can combine motoring and grid-charging functions. However, this machine structure is different to a SRM and its zero-sequence current increases the control complexity. A $2.3 \mathrm{~kW}$ SRM with an asymmetric half-bridge converter is proposed in [24], which can provide on-board charging and power factor correction functions. But its front-end DC-DC converter is externally equipped, making this topology less practical and flexible for the target application. Based on the same motor, an integrated SRM-charger is developed to use standard three-phase intelligent power modules (IPMs) in a four-phase full-bridge converter [25]. In order to improve the converter reliability, papers [28], [29] propose a cascaded high-frequency resonant converter with a small DC-link capacitor. In paper [30], a maximum power tracking technology for a wide state-of-charge (SoC) range is developed to improve energy efficiency at both heavy and light load conditions. This paper presents a split converter-fed SRM with a central tapped 
winding of the motor to support DC and AC grid charging, without recourse to charging infrastructure. This will meet versatile charging requirements at almost no additional hardware investment.

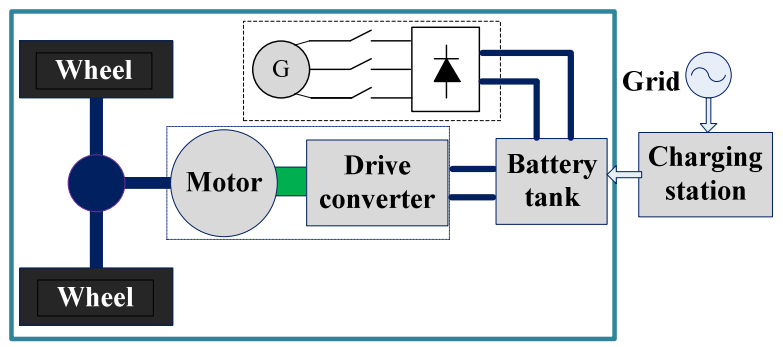

Fig. 1. Basic EV/HEV drive structure.

\section{SRM TOPOLOGY WITH CENTRAL TAPPED WINDINGS}

In order to realize grid charging without the need for charging stations, a split-phase structure is developed for permanent magnet motors [23], [27]; but they are suited only for AC charging and need special design of the winding structure. In this paper, a four-phase 8-slot/6-pole (8/6) SRM is chosen. Fig. 2(a) and (b) show the central-tapped node of the SRM and the asymmetrical half-bridge drive topology, respectively. It can be seen that the central-tapped node is easily arranged.

In order to realize the modular structure of the motor drive, an asymmetric half-bridge converter topology is developed, as shown in Fig. 3. $S_{0} \sim S_{7}$ are eight MOSFETs; $D_{0} \sim D_{7}$ are eight freewheeling diodes; $C_{a b}$ and $C_{c d}$ are two input filter capacitors. $L_{a 14}, L_{a 23}, L_{b 14}, L_{b 23}, L_{c 14}, L_{c 23}, L_{d 14}$ and $L_{d 23}$ are the winding inductances of phases $A, B, C$ and D, respectively. $N_{A}, N_{B}, N_{C}$ and $N_{D}$ are the central tapped nodes of the four phases. Clearly, phases $\mathrm{A}$ and $\mathrm{B}$ share the battery voltage $E_{1}$; phases $\mathrm{C}$ and D share $E_{2}$. Converter I drives phases A and B of the SRM while converter II drives phases $\mathrm{C}$ and $\mathrm{D}$.

The converter operates in two modes: driving and charging. In the driving mode, the charging plug is idle and the converter topology is equivalent to a traditional asymmetric half-bridge topology. Since $\mathrm{N}_{\mathrm{A}}$ and $\mathrm{N}_{\mathrm{D}}$ do not connect to one another, there is no current flowing between $\mathrm{N}_{B}$ and $\mathrm{N}_{C}$, i.e., converters I and II operate independently. In the charging mode, the charging plug is connected to an external power source. Converters I and II act as charging converters.

\section{SRM DRIVE CONTROL SCHEME}

This section introduces the split converter topology control strategy under a driving mode, battery balance in the standstill scenario and an unequal SoC in the driving mode.
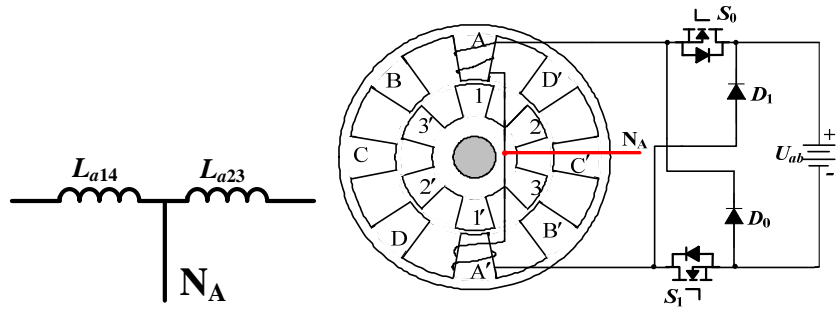

(a) Motor with a central-tapped node Fig. 2. The SRM with a central-tapped node.

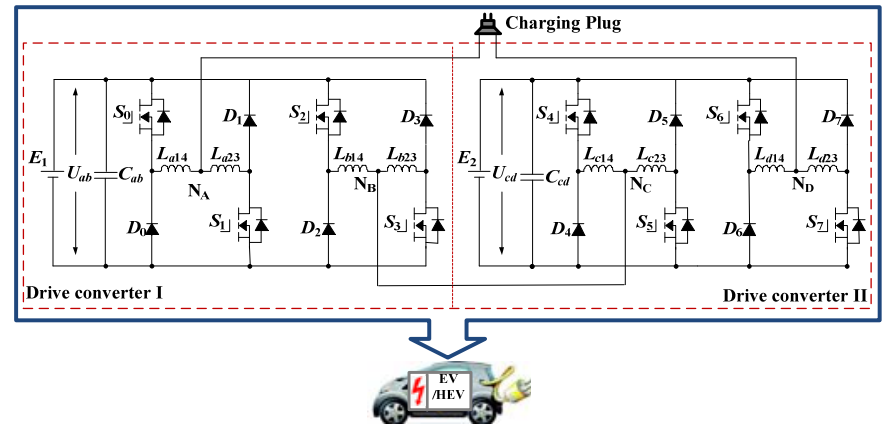

Fig. 3. The proposed topology with a central-tapped node.

\section{A. Drive Control Strategy Based on the Split Topology}

The phase voltage balance is given by:

$$
\pm U_{a b}=R i+L(\theta) \frac{d i}{d t}+i \omega \frac{d L(\theta)}{d \theta}
$$

where $U_{a b}$ is the phase voltage, $R$ is the phase resistance, $L$ is the phase inductance, $i$ is the phase current, $\theta$ is the rotor angular position, and $\omega$ is the angular speed.

When a motor phase is powered by a positive dc-link voltage $\left(+U_{a b}\right)$, this phase works in the excitation mode and the battery is discharging. In the demagnetization or regenerative braking mode, the phase is subject to a negative dc-link voltage $\left(-U_{a b}\right)$ and the battery is charging.

The phase inductance varies as a function of the rotor position, and the electromagnetic torque is expressed as

$$
T_{e}=\frac{1}{2} i^{2} \frac{d L(\theta)}{d \theta}
$$

where $T_{e}$ is the phase electromagnetic torque.

A positive torque is generated $\left(T_{e}>0\right)$ when a current is applied to the phase winding in the inductance ascending region $(\mathrm{d} L / \mathrm{d} \theta>0)$. Otherwise, a negative torque is produced $\left(T_{e}<0\right)$ when the current is applied in the inductance descending region $(\mathrm{d} L / \mathrm{d} \theta<0)$. Hence, the electromagnetic torque direction can be controlled by altering turn-on angle $\left(\theta_{\text {on }}\right)$ and turn-off angle $\left(\theta_{\text {off }}\right)$.

The mechanical motion equation of the SRM is given by:

$$
J \frac{d \omega}{d t}+B \omega=\sum T_{e k}-T_{l}
$$

where $J$ is the combined moment of inertia of the motor and load, $B$ is the combined friction coefficient of the motor and load, $\sum T_{e k}$ is the total electromagnetic torque, and $T_{l}$ is the load torque.

Fig. 4 shows a control block diagram of the SRM in motoring and regenerative braking modes. The four-phase power converter is split into two double-phase converters (one for phases A and B and another for phases C and D). As illustrated in the figure, $E_{1}$ is applied to converter I and $E_{2}$ to converter II. Converter I or converter II can be chosen to work in the regenerative braking mode to generate the braking torque and recover the braking energy while another one is disabled deliberately. Thus, this converter can realize battery SoC balance in the driving mode.

The outer loop is a motor speed controller which reads the rotor angular position and calculates the motor speed for closed-loop control. The operational modes can be selected by controlling turn-on and turn-off angles.

If the speed demand is greater than the actual speed, the windings of active phases in the ascending-inductance 
region are energized to produce a positive torque in the motoring mode, and the battery is discharged. Otherwise, they produce a negative torque in the regenerative braking mode, and the battery is charged.

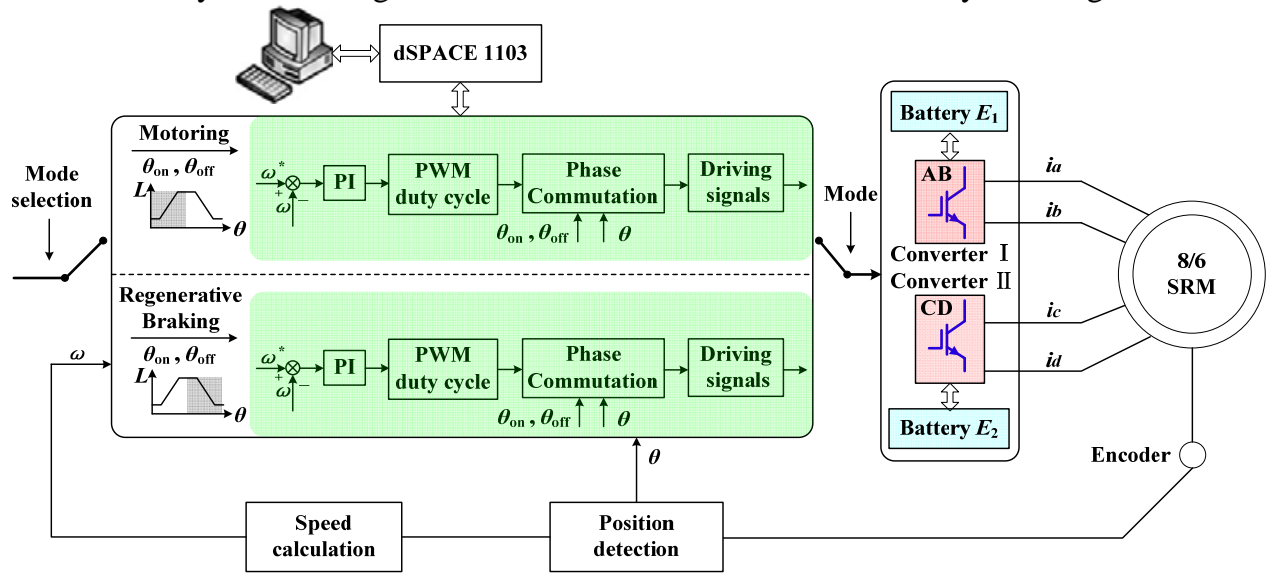

Fig. 4. Control block diagram of the SRM.

The SRM has good fault tolerance ability owing to its phase independence. In case a pair of phases are faulty (say, $\mathrm{C}-\mathrm{D})$, the motor can still operate while the currents in the healthy phases (A-B) are increased.

\section{B. Battery Voltage Balance Control in the Standstill Scenario}

Due to a voltage difference between the batteries and phase windings, the batteries may have different SoC. In order to equalize the battery voltages between phases, node $\mathrm{N}_{\mathrm{A}}$ is connected to $\mathrm{N}_{\mathrm{D}}$ in the standstill scenario, as presented in Fig. 5(a).

When the SoC of battery $E_{1}$ is higher than that of battery $E_{2}$, the corresponding charging state circuits are illustrated in Fig. 5(b) and (c). In Fig. 5(b), $S_{0}$ and $S_{3}$ conduct to charge winding inductances. In Fig. 5(c), the energy stored in winding inductors is discharged to battery $E_{2}$.

When the SoC of battery $E_{1}$ is lower than that of battery $E_{2}, S_{1}$, $S_{5}, S_{6}$ are switched on to charge winding inductances. By switching off devices $S_{1}$ and $S_{6}$, battery $E_{1}$ is charged.

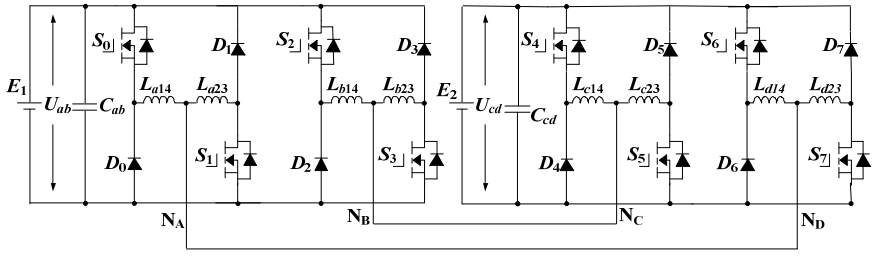

(a) Equalization of the battery voltages

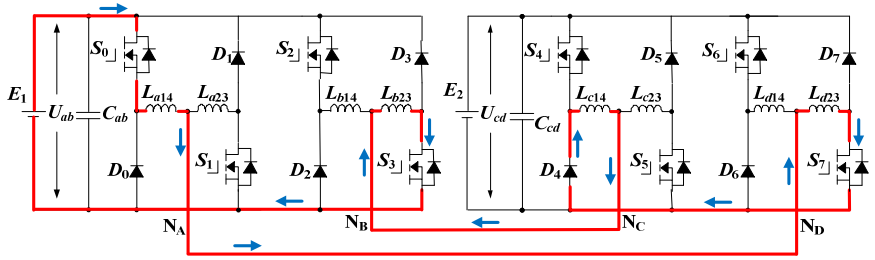

(b) State of excitation of phase windings

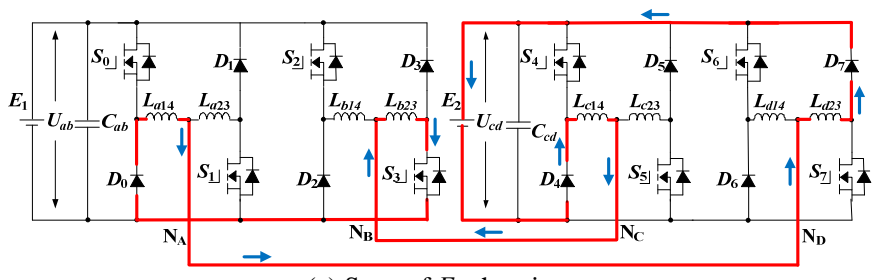

(c) State of $E_{2}$ charging

Fig. 5. Battery voltage balance at working states.

\section{Unequal SoC in the Driving Mode}

Owing to the fluctuating motor parameters and battery characteristics, the two batteries may also have different SoC in the driving mode. The average phase voltage in the excitation region for phases $\mathrm{A}$ and $\mathrm{C}$ are expressed as

$$
\begin{aligned}
& U_{a}=D U_{a b}=R_{a} i+L_{a}(\theta) \frac{d i_{a}}{d t}+i_{a} \omega \frac{d L_{a}(\theta)}{d \theta} \\
& U_{c}=D U_{c d}=R_{c} i+L_{c}(\theta) \frac{d i_{c}}{d t}+i_{c} \omega \frac{d L_{c}(\theta)}{d \theta}
\end{aligned}
$$

where $U_{a}$ and $U_{c}$ are the phase A and C voltages, respectively; $D$ is the duty-cycle for the voltage PWM control;

Given that converters I and II share the same PWM duty-cycle, the average voltage for phase $\mathrm{A}$ is higher than phase $\mathrm{C}$, leading to an imbalance between phases A and C. However, the system can still operate steadily because of a closed-loop control algorithm.

By the current regulation control, the four phase currents are balanced out although the input voltages for converters I and II are different.

\section{CHARGING CONTROL STRATEGY}

The proposed dual split converter can support both DC and AC charging.

\section{A. DC Power Charging}

The batteries can be charged by low-voltage DC power (e.g. from a DC microgrid), as shown in Fig. 6. This topology has a boost voltage characteristic and thus the DC source voltage should be lower than the sum of $U_{a b}$ and $U_{c d}$. Usually, the available DC source voltage is lower than the twice on-board battery voltage in EV/HEV, which makes the proposed method suitable for the common DC sources. There are four basic working states, as illustrated in Fig. 7.

In working stage 1 , only $S_{3}$ and $S_{7}$ conduct. The DC source charges the winding inductances $L_{a 14}, L_{b 23}, L_{c 14}$ and $L_{d 23}$; the corresponding voltage equation can be expressed as:

$$
U_{d c}=\left(L_{a 14}+L_{b 23}+L_{c 14}+L_{d 23}\right) \frac{d i_{s}}{d t}
$$

where $U_{d c}$ is the external DC source voltage, and $i_{s}$ is the output current of the DC source. 


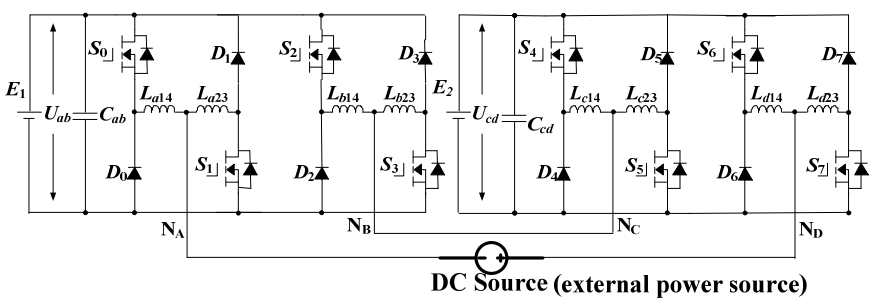

Fig. 6. Charging batteries by DC power.

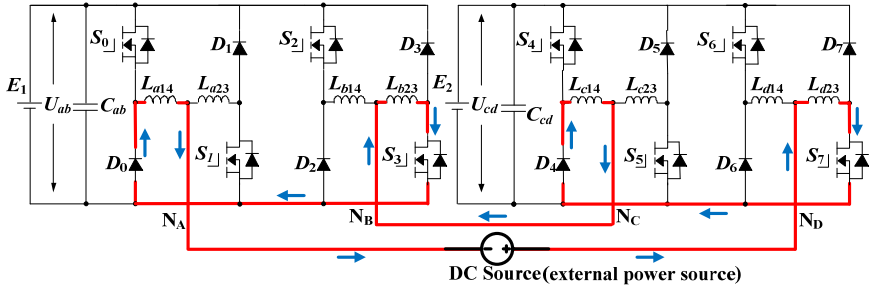

(a) State 1

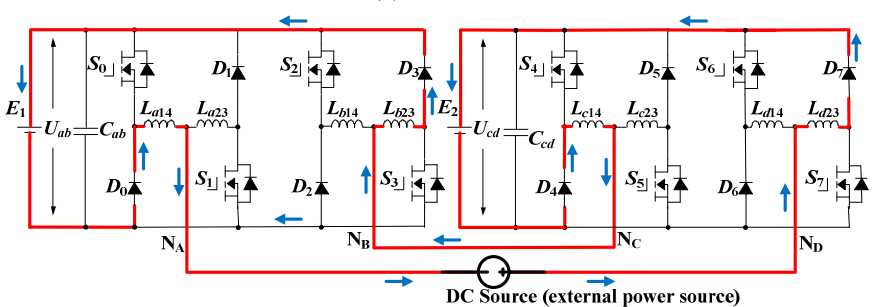

(b) State 2

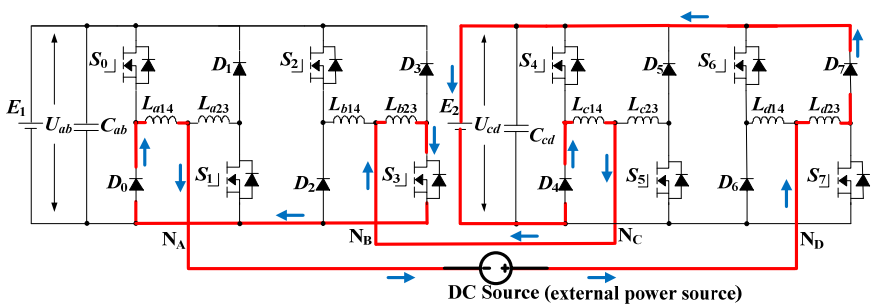

(c) State 3

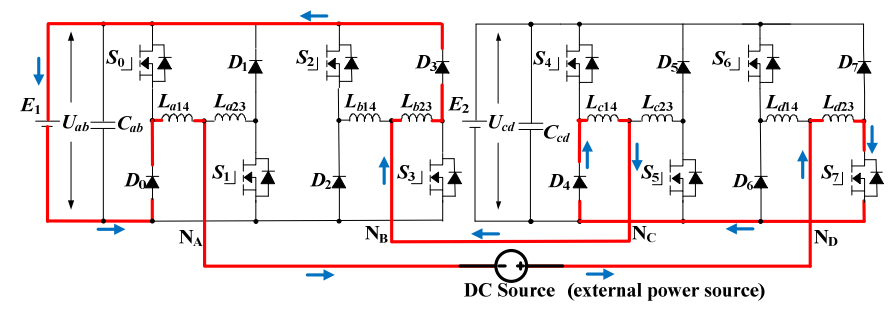

(d) State 4

Fig. 7. Working stages in low DC voltage charging.

In working stage 2, all MOSFETs stop conducting. The DC source and winding inductances $\left(L_{a 14}, L_{b 23}, L_{c 14}\right.$ and $\left.L_{d 23}\right)$ discharge the energy to the two batteries at the same time.

$$
U_{d c}=\left(L_{a 14}+L_{b 23}+L_{c 14}+L_{d 23}\right) \frac{d i_{s}}{d t}+U_{a b}+U_{c d}
$$

In working stage $3, S_{3}$ conducts. The DC source and winding inductances ( $L_{a 14}, L_{b 23}, L_{c 14}$ and $L_{d 23}$ ) discharge the energy to battery $E_{2}$ :

$$
U_{d c}=\left(L_{a 14}+L_{b 23}+L_{c 14}+L_{d 23}\right) \frac{d i_{s}}{d t}+U_{c d}
$$

In working stage $4, S_{7}$ conducts. The DC source and winding inductances ( $L_{a 14}, L_{b 23}, L_{c 14}$ and $L_{d 23}$ ) discharge the energy to battery $E_{1}$ :

$$
U_{d c}=\left(L_{a 14}+L_{b 23}+L_{c 14}+L_{d 23}\right) \frac{d i_{s}}{d t}+U_{a b}
$$

\section{B. AC Power Charging}

The batteries can be charged by low-voltage single-phase grid, as shown in Fig. 8(a). This is a typical cascaded multi-level topology. The output voltage is at five levels: $0, U_{a b}$, $U_{a b}+U_{c d},-U_{a b}$ and $-\left(U_{a b}+U_{c d}\right)$. In order to decrease the switching frequency and improve the power quality, the multi-stage hysteresis control is employed in the charging control, as shown in Fig. 8(b). SoC $\mathrm{S}_{\mathrm{I}}$ stands for the SoC of battery $E_{1}$ and $S_{\text {II }}$ for battery $E_{2}$. In the proposed control strategy, the influence of SoC is considered. When the two batteries have the same SoC, the energy charged to batteries $E_{1}$ and $E_{2}$ is the same. Fig. 9 presents the output voltage over one line frequency cycle. In a half cycle, there are five output voltage stages to realize the multi-level output, which decreases the switching frequency and total harmonic distortion (THD). Owing to symmetry of the switching actions, the energy charged to battery $E_{1}$ is identical to battery $E_{2}$. The corresponding switching device actions are listed in Table. I.

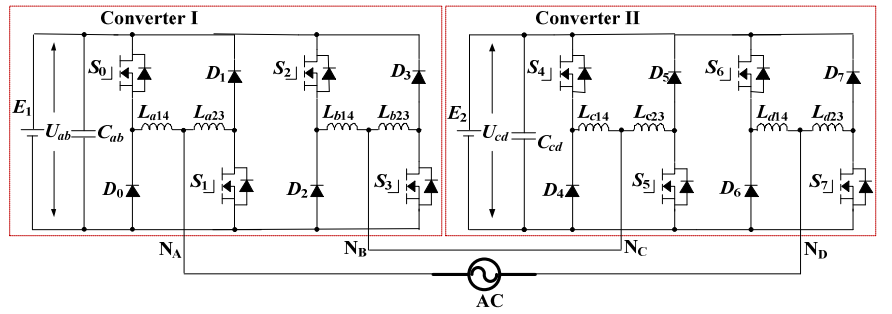

(a) Charging batteries by AC power.

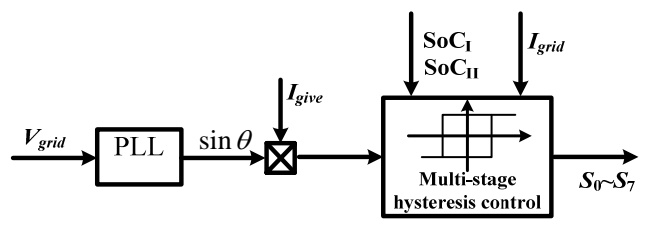

(b) Multi-stage hysteresis control.

Fig. 8. AC charging topology and control strategy.

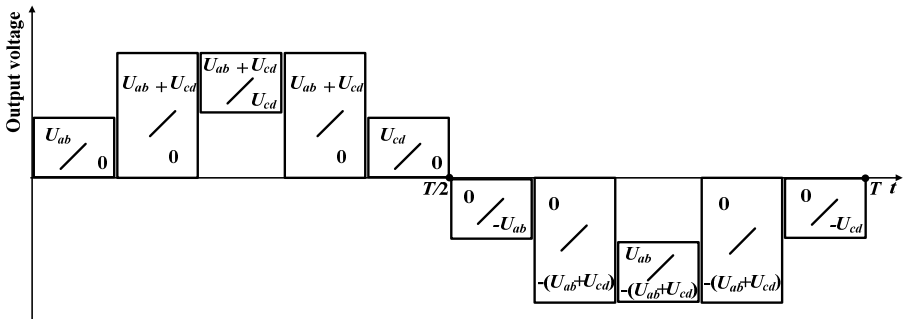

Fig. 9. Output voltage levels under the multi-stage hysteresis control $\left(\mathrm{SoC}_{\mathrm{l}}=\right.$ SoC $C_{\text {III }}$.

TABLE I

Multi-Stage Hysteresis Control (Positive Half CyCle)

\begin{tabular}{|c|c|c|c|c|}
\hline \multirow{2}{*}{ Stage } & \multicolumn{2}{|c|}{ High voltage level } & \multicolumn{2}{c|}{ Low voltage level } \\
\cline { 2 - 5 } & Output voltage & $\begin{array}{c}\text { Conducting } \\
\text { devices }\end{array}$ & $\begin{array}{c}\text { Output } \\
\text { voltage }\end{array}$ & $\begin{array}{c}\text { Conducting } \\
\text { Devices }\end{array}$ \\
\hline 1 & $U_{a b}$ & $D_{1}, S_{3}, S_{5}, S_{7}$ & 0 & $S_{1}, S_{3}, S_{5}, S_{7}$ \\
\hline 2 & $U_{a b}+U_{c d}$ & $D_{1}, S_{3}, D_{5}, S_{7}$ & 0 & $S_{1}, S_{3}, S_{5}, S_{7}$ \\
\hline 3 & $U_{a b}+U_{c d}$ & $D_{1}, S_{3}, D_{5}, S_{7}$ & $U_{c d}$ & $S_{1}, S_{3}, D_{5}, S_{7}$ \\
\hline 4 & $U_{a b}+U_{c d}$ & $D_{1}, S_{3}, D_{5}, S_{7}$ & 0 & $S_{1}, S_{3}, S_{5}, S_{7}$ \\
\hline 5 & $U_{c d}$ & $S_{1}, S_{3}, D_{5}, S_{7}$ & 0 & $S_{1}, S_{3}, S_{5}, S_{7}$ \\
\hline
\end{tabular}

The switching frequency for the three stages is given by: 
IEEE TRANSACTIONS ON INDUSTRIAL ELECTRONICS

$$
\begin{gathered}
f_{1,5}=\frac{U_{g r i d}\left(U_{a b}-U_{g r i d}\right)}{H L_{A B C D} U_{a b}} \\
f_{2,4}=\frac{U_{g r i d}\left(U_{a b}+U_{c d}-U_{g r i d}\right)}{H L_{A B C D}\left(U_{a b}+U_{c d}\right)} \\
f_{3}=\frac{\left(U_{a b}+U_{c d}-U_{g r i d}\right)\left(U_{g r i d}-U_{a b}\right)}{H L_{A B C D} U_{c d}}
\end{gathered}
$$

where $f_{1,5}$ is the switching frequency for stages 1 and $5 ; f_{2,4}$ is for stages 2 and $4 ; f_{3}$ is for stage 3 . $U_{\text {grid }}$ is the instantaneous grid voltage; $H$ is the bandwidth of the hysteresis control; $L_{A B C D}$ is the circuit inductance, which is the sum of half inductance (e.g. $L_{a 14}$ ) of phases A, B, C and D.

By the multi-stage hysteresis control, the switching frequency of stages 1,3 and 5 can be decreased. The switching frequency of stages 2 and 4 is the same as in the traditional hysteresis control.

Table II presents the unequal SoC charging strategy. When SoC $_{\text {uab }}<$ SoC $_{\text {ucd }}$, battery $E_{1}$ is charged with more energy than battery II. In stages $1 \sim 5$, battery $E_{1}$ is charged by the grid; while battery $E_{2}$ is charged in stages $2 \sim 4$. When $\operatorname{SoC}_{\mathrm{I}}>\mathrm{SoC}_{\mathrm{II}}$, battery $E_{1}$ is charged less than battery $E_{2}$. In stages $1 \sim 5$, battery $E_{2}$ is charged by the grid; while battery $E_{1}$ is charged in stages $2 \sim 4$.

Fig. 10 shows the simulation results of AC charging under the condition of $\mathrm{SoC}_{\mathrm{I}}<\mathrm{SoC}_{\mathrm{II}}$. The grid frequency is set to $50 \mathrm{~Hz}$, the peak voltage is $18.7 \mathrm{~V}$ and the battery voltage is $12 \mathrm{~V}$. By using the multi-stage hysteresis control, the switching frequency can be decreased; and all switching devices have a half cycle in idle condition that is helpful to decrease the thermal stress on the switching devices. Fig. 10(c) presents the central-tapped node voltages and the grid-side current by using the proposed hysteresis control method. The corresponding THD is $1.57 \%$ and the power factor is 1 .

\section{Influence of Varying Phase Inductances}

In both DC and AC charging conditions, the circuit inductance is needed for control loop design. Due to the doubly saliency characteristics of the SRM, the phase inductances vary with the rotor position all the time. Fig. 11 shows the four phase inductances in the half period. Fortunately, the sum of the four inductances becomes much stable than phase inductances over the rotor position. As a result, it is used for control loop design.

TABLE II

UnEQUAL SOC CHARging STRATEgy (Positive HALF CyClE)

\begin{tabular}{|c|c|c|c|c|}
\hline & \multicolumn{2}{|c|}{ SoC $_{\mathrm{I}}<\mathrm{SoC}_{\mathrm{II}}$} & \multicolumn{2}{c|}{ SoC $_{\mathrm{I}}>\mathrm{SoC}_{\mathrm{II}}$} \\
\hline Stage & $\begin{array}{c}\text { High voltage } \\
\text { level }\end{array}$ & $\begin{array}{c}\text { Low voltage } \\
\text { level }\end{array}$ & $\begin{array}{c}\text { High voltage } \\
\text { level }\end{array}$ & $\begin{array}{c}\text { Low voltage } \\
\text { level }\end{array}$ \\
\hline 1 & $U_{a b}$ & 0 & $U_{c d}$ & 0 \\
\hline 2 & $U_{a b}+U_{c d}$ & 0 & $U_{a b}+U_{c d}$ & 0 \\
\hline 3 & $U_{a b}+U_{c d}$ & $U_{a b}$ & $U_{a b}+U_{c d}$ & $U_{c d}$ \\
\hline 4 & $U_{a b}+U_{c d}$ & 0 & $U_{a b}+U_{c d}$ & 0 \\
\hline 5 & $U_{a b}$ & 0 & $U_{c d}$ & 0 \\
\hline
\end{tabular}
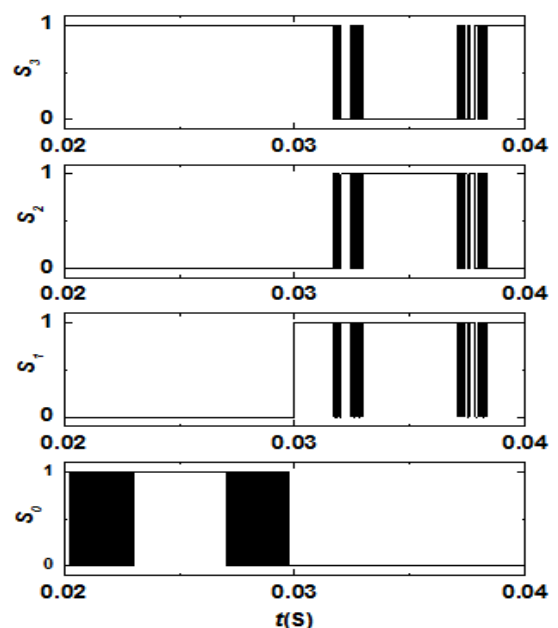

(a) $S_{0} \sim S_{3}$
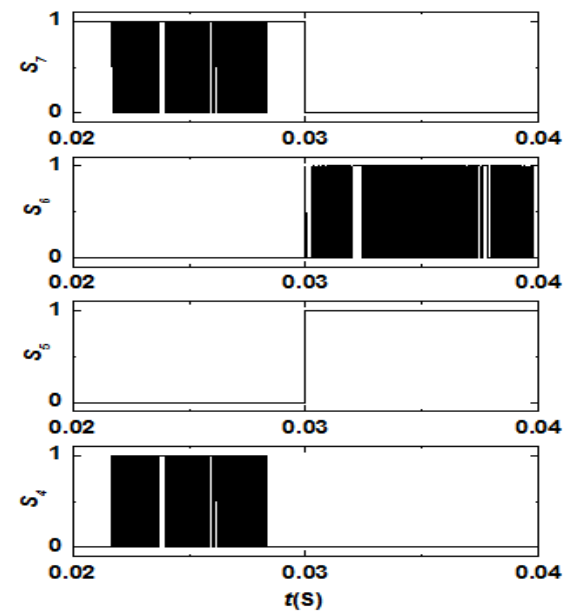

(b) $S_{4} \sim S_{7}$
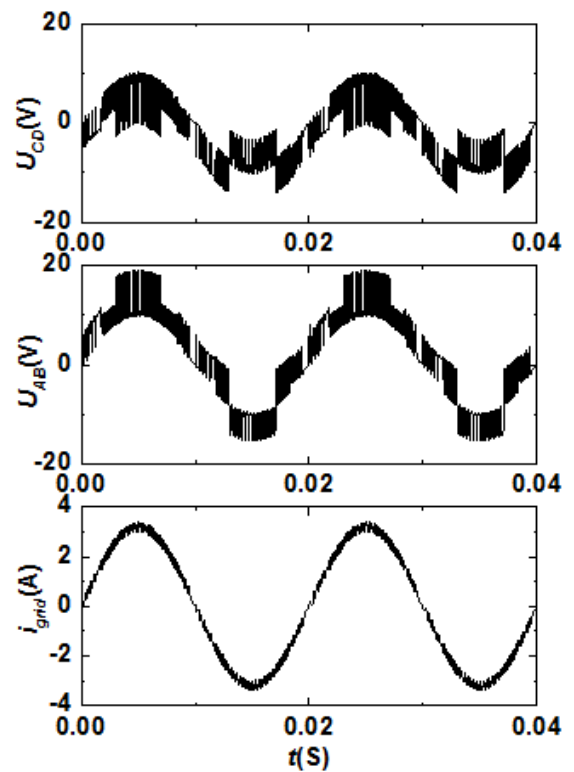

(c) Central-taped node voltages and grid current Fig.10. Simulation results for AC charging.

\section{EXPERIMENTAL VALIDATION}

In order to verify the proposed topology and charging strategy, an experimental setup is developed, as shown in Fig. 12. The test motor is an 8/6 SRM with the ratings of: $24 \mathrm{~V}$ voltage, $150 \mathrm{~W}$ power and $1500 \mathrm{rpm}$ speed; the central points of 
the windings are taken out and tapped as shown in Fig. 12. A dSPACE-based controller and two $12 \mathrm{~V}$ batteries are employed in the experimental tests.

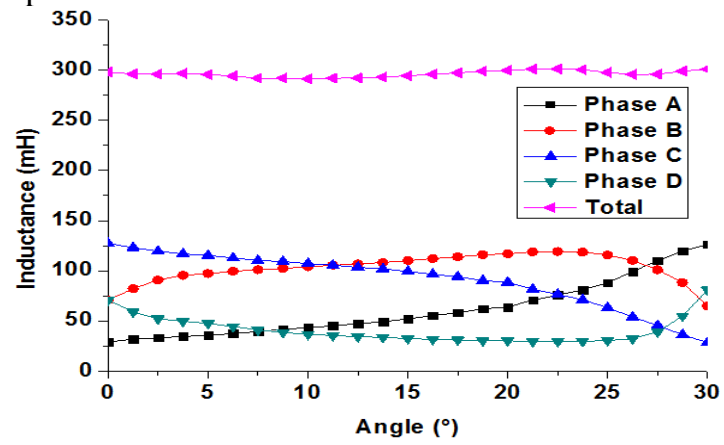

Fig. 11. The inductances as a function of the rotor position.

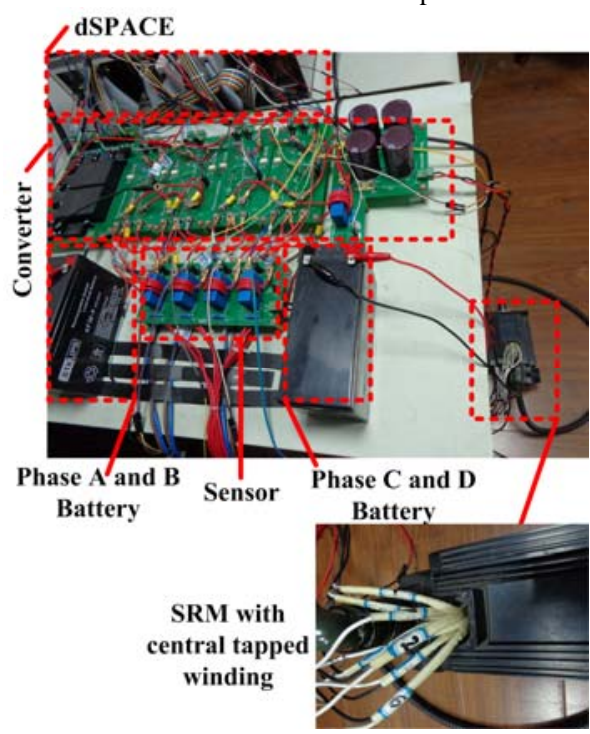

Fig. 12. Experimental setup of the proposed system.

Fig. 13 shows the phase current and speed waveforms in the driving mode at different operating conditions. A PI controller is used to implement the closed-loop scheme via the PWM voltage regulation. The unaligned position of the stator and rotor of SRM is defined as the start of the turn-on angle. Fig. 13(a) illustrates that the motor works steadily in the motoring mode at the speed of $800 \mathrm{rpm}$, where the turn-on angle and turn-off angle are set to $0^{\circ}$ and $28^{\circ}$, respectively. The speed follows the given reference well, and the four-phase currents are fairly balanced. When the motor works in the regenerative braking mode, the turn-on and turn-off angles are set to $30^{\circ}$ and $55^{\circ}$, respectively. The four phases are energized to produce a negative torque; the braking energy flows back to the two batteries and the speed falls sharply, as shown in Fig. 13(b). In this state, the two batteries are charged without restraints. Fig. 13(c) shows the unequal braking mode when phases A and B are enabled and phases $C$ and $D$ are disabled. Owing to the split converter topology, the braking energy can flow to the selected battery through the active converter. The fault tolerance operation of the motor is shown in Fig. 13(d). When phases C and $\mathrm{D}$ are subjected to an open-circuit fault, the motor can still operate steadily while increasing the currents in phases A and B. By comparing the results between the normal condition (Fig. 13(a)) and the fault condition (Fig. 13(d)), it can be seen that phase A and B currents increase from 0.7 to $1 \mathrm{~A}$ to ensure the continuous operation of the motor drive with faulted phases $\mathrm{C}$ and $\mathrm{D}$.

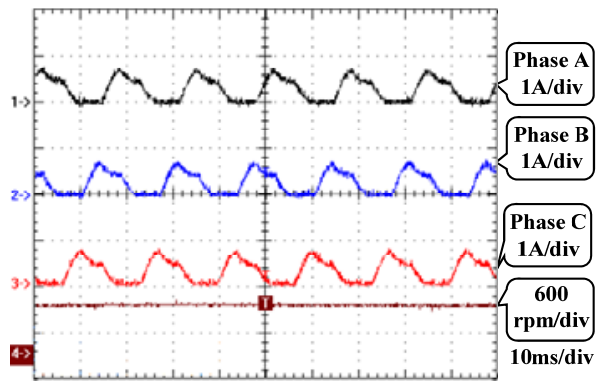

(a) Normal operation

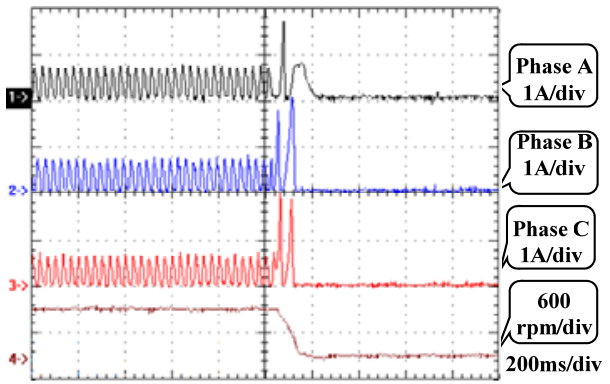

(b) Braking under normal condition

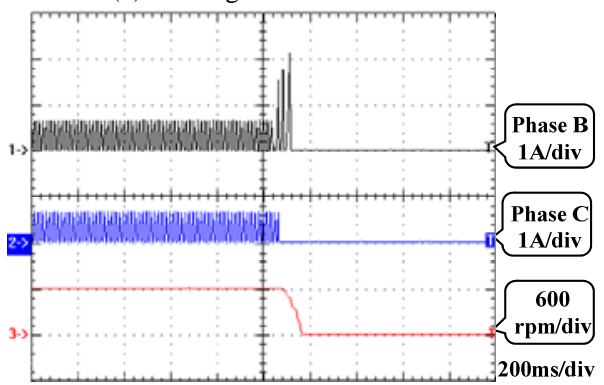

(c) Braking under unequal SoC of the batteries

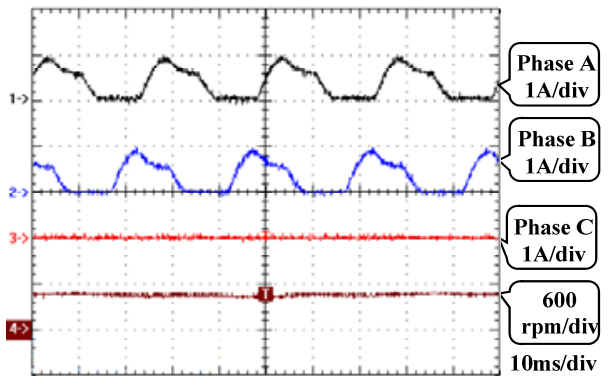

(d) Fault tolerant operation

Fig. 13. Experimental results in the driving mode.

Fig. 14 presents the experiment results for unequal voltage sources under the driving mode. A $12 \mathrm{~V}$ battery and a programmable DC source are employed as the source of converters I and II, respectively. Fig. 14(a) and (b) present the waveforms under the PWM control strategy. The amplitude of phase A current is slightly higher than that of phase $\mathrm{C}$; the voltage of $E_{2}$ is $20 \%$ (Fig. 14(a)) and 10\% (Fig. 14(b)) lower than $E_{1}$. Even so, the system can operate steadily because of the closed-loop control algorithm.

Fig. 14(c)-(d) show the experimental results under a current chopping control (CCC) strategy. The voltage of $E_{2}$ is $20 \%$ (Fig.14(c)) and $10 \%$ (Fig. 14(d)) lower than $E_{1}$. Clearly, the voltage difference has little impact on the motor performance in the driving mode. 
IEEE TRANSACTIONS ON INDUSTRIAL ELECTRONICS

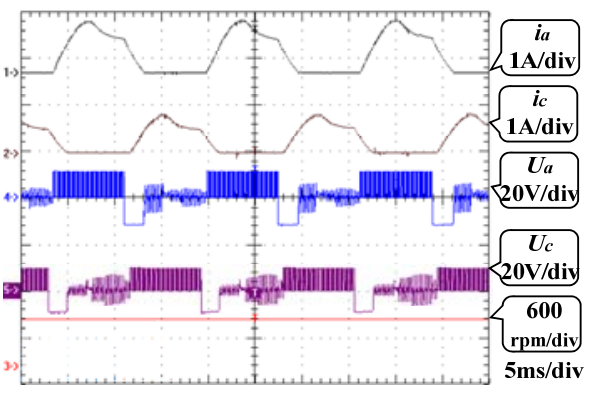

(a) PWM 12 V $\left(E_{1}\right)-9.6 \mathrm{~V}\left(E_{2}\right)$

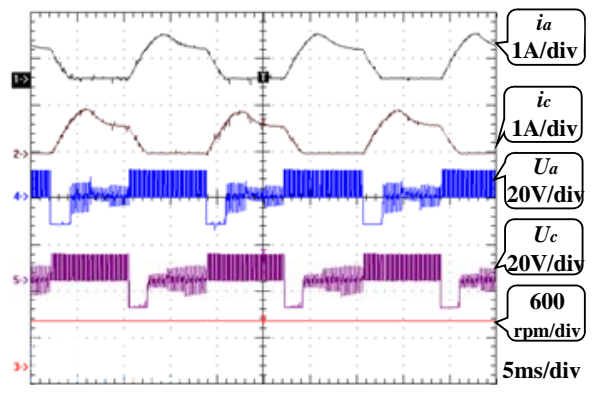

(c) PWM $12 \mathrm{~V}\left(E_{1}\right)-12 \mathrm{~V}\left(E_{2}\right)$

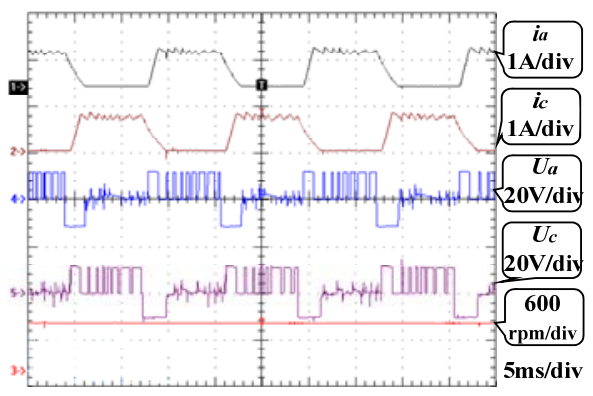

(e) CCC $12 \mathrm{~V}\left(E_{1}\right)-10.8 \mathrm{~V}\left(E_{2}\right)$

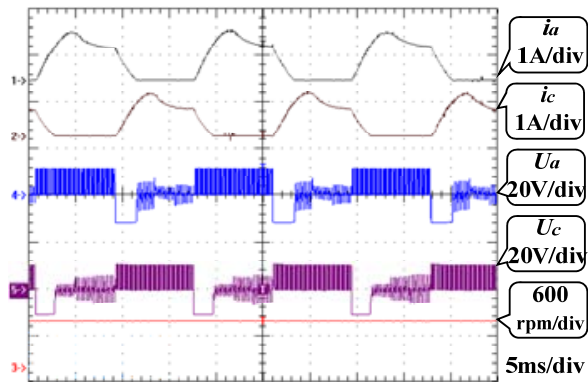

(b) PWM $12 \mathrm{~V}\left(E_{1}\right)-10.8 \mathrm{~V}\left(E_{2}\right)$

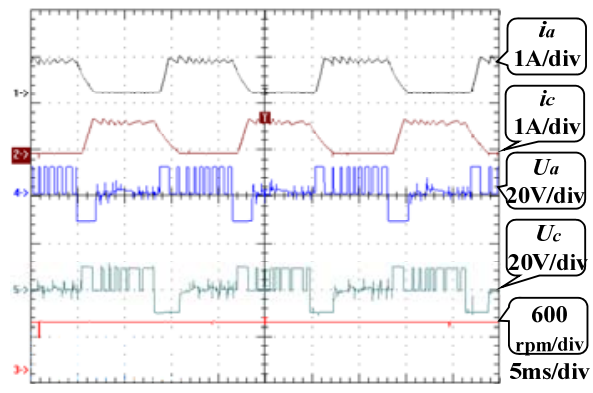

(d) CCC $12 \mathrm{~V}\left(E_{1}\right)-9.6 \mathrm{~V}\left(E_{2}\right)$

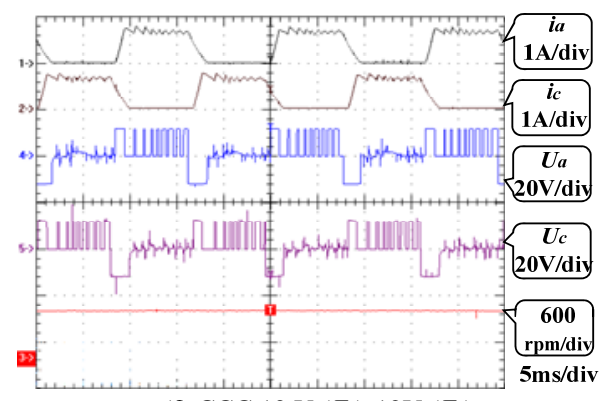

(f) CCC $12 \mathrm{~V}\left(E_{1}\right)-12 \mathrm{~V}\left(E_{2}\right)$

Fig. 14. PWM and CCC control under unequal and equal voltage sources.

Fig. 15(a) presents the experimental results for balancing the charging energy for the two batteries ( $E_{1}$ and $\left.E_{2}\right)$. Fig. 15(b) shows the experiment results under DC charging. An external $15 \mathrm{~V}$ source is employed as the charging source and $i_{s}$ denotes its charging current. Fig.15(c) shows the DC source current, terminal voltage of battery 1 , and encoder output voltage under DC charging, where $U_{z}$ is the rotor encoder signal. It is zero because the rotor is at standstill. Clearly, motor torque has no influence on the charging performance at the DC power charging condition.

Fig. 16(a) illustrates the AC grid charging performance under the equal SoC condition, in which the grid parameters are $50 \mathrm{~Hz}$ and $18.7 \mathrm{~V}$ (peak voltage). By the improved hysteresis control, the converter total harmonic distortion (THD) is 3.7\% (see Fig. 16(b)), which meets the requirement of the international standards IEC61727 and IEEE1547. Fig. 16(c) and (d) show the driving signals of switching devices $S_{0}-S_{7}$. Compared with simulation results, the switching frequency in experiments is slightly lower, due to a difference in simulation model and actual motor parameters. The THD of the grid current is also lower than that in simulation.

Fig. 17 presents the waveforms of AC charging under unequal SoC conditions. The control strategy deals with the battery difference in SoC. The voltage is $12 \mathrm{~V}$ for $E_{1}$ and $10.8 \mathrm{~V}$ for $E_{2}$. By regulating the switching actions of $S_{1}$ and $S_{5}$, more energy can be charged to $E_{2}$. In Fig.17(c), $U_{Z}$ keeps zero since the motor is at standstill in the charging process. Similar to DC charging, motor torque has no influence on EV charging at the AC power charging condition.

\section{CONCLUSION}

In order to speed up the market acceptance of EVs/HEVs, the capital cost in charging infrastructure needs to lower as much as possible. This paper has presented an improved asymmetric half-bridge converter-fed SRM drive to provide both driving and on-board DC and AC charging functions so that the reliance on off-board charging stations is reduced.

The main contributions of this paper are: (i) it combines the split converter topology with central tapped SRM windings to improve the system reliability. (ii) the developed control strategy enables the vehicle to be charged by both DC and AC power subject to availability of power sources. (iii) the battery energy balance strategy is developed to handle unequal SoC scenarios. Even through a voltage imbalance of up to $20 \%$ in the battery occurs, the impact on the driving performance is rather limited. (iv) the state-of-charge of the batteries is coordinated by the hysteresis control to optimize the battery performance; the THD of the grid-side current is $3.7 \%$ with a lower switching frequency. 
This article has been accepted for publication in a future issue of this journal, but has not been fully edited. Content may change prior to final publication. Citation information: DOI 10.1109/TIE.2015.2426142, IEEE Transactions on Industrial Electronics

IEEE TRANSACTIONS ON INDUSTRIAL ELECTRONICS

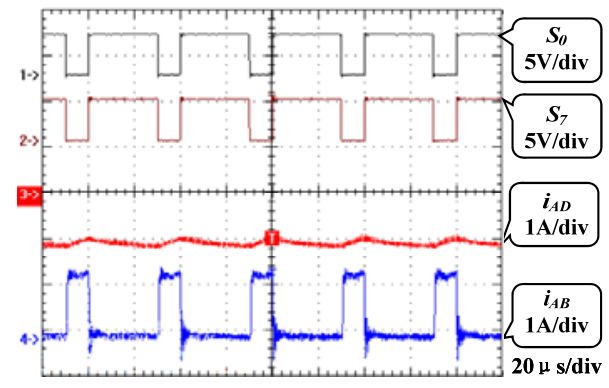

(a) Equalization of battery voltages

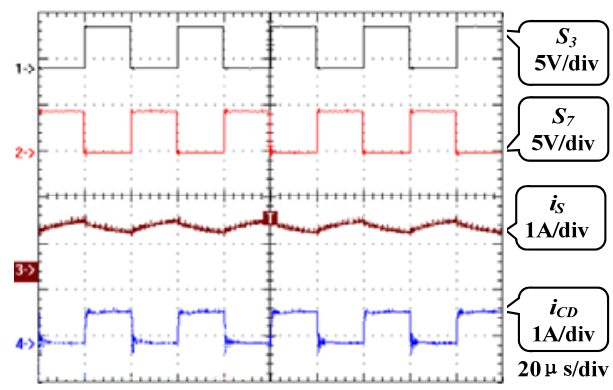

(b) DC charging

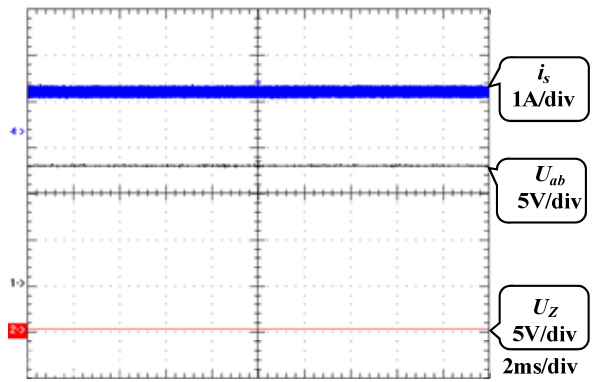

(c) The DC source current, terminal voltage of battery I, and encoder output voltage

Fig. 15. Experimental results for DC source charging

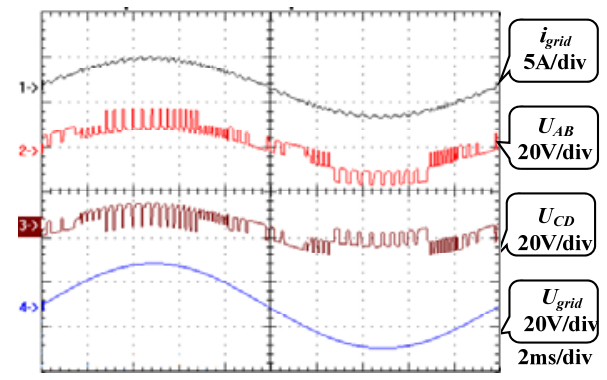

(a) AC charging

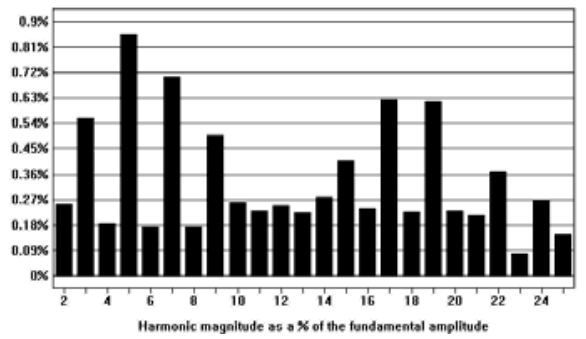

(b) Harmonic content of the grid-current

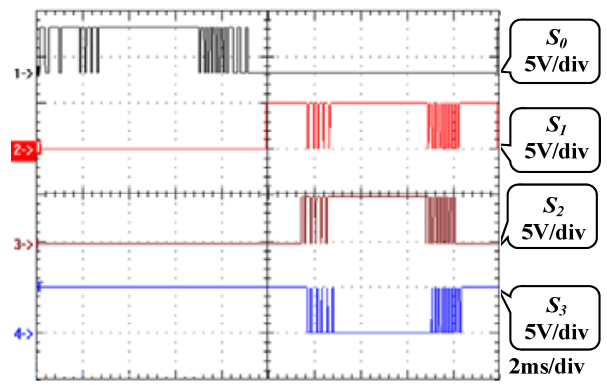

(c) $S_{0} \sim S_{3}$

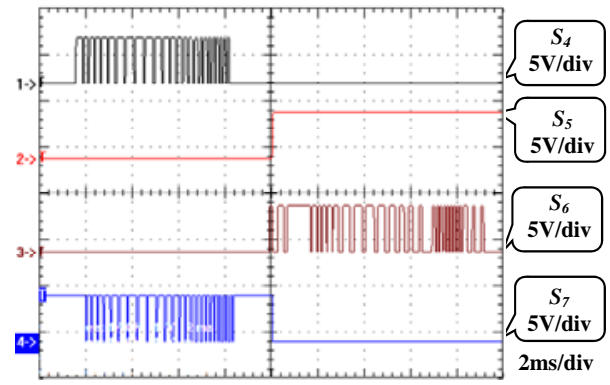

(d) $S_{4} \sim S_{7}$

Fig. 16. Experimental results for balanced AC source charging

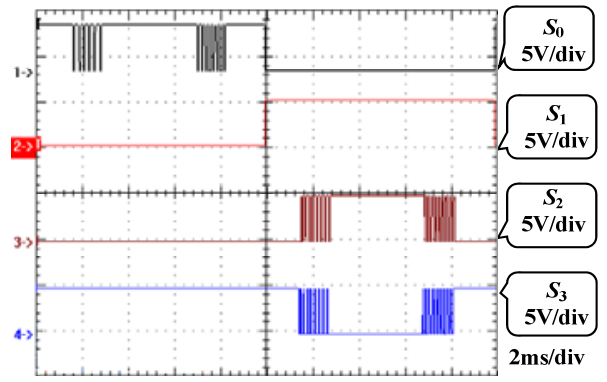

(a) $S_{0} \sim S_{3}$

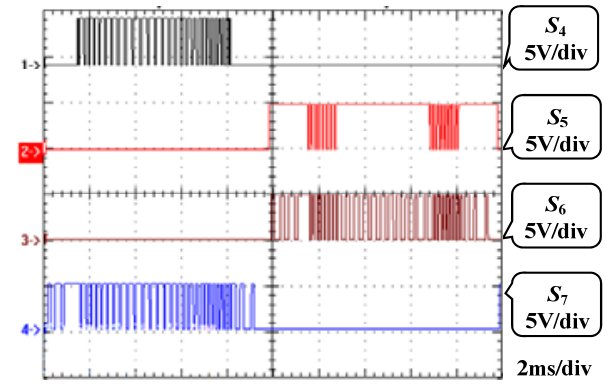

(b) $S_{4} \sim S_{7}$

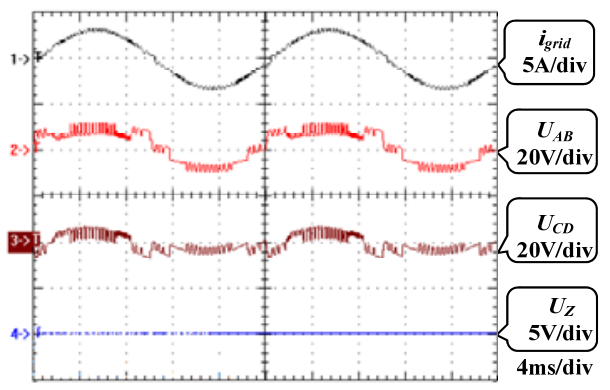

(c) AC charging

Fig. 17. Experimental results for unequal SoC AC charging.

It needs to point out that this is a proof-of-concept study based on a $150 \mathrm{~W}$ SRM and low-voltage power for simulation 
and experiments. In the further work, the test facility will be scaled up to $50 \mathrm{~kW}$.

\section{REFERENCES}

[1] B. K. Bose, "Global energy scenario and impact of power electronics in 21st Century,” IEEE Trans. Ind. Electron., vol. 60, no. 7, pp. 2638- 2651, Jul. 2013.

[2] J. de Santiago, H. Bernhoff, B. Ekergård, S. Eriksson, S. Ferhatovic, R. Waters, and M. Leijon, "Electrical motor drivelines in commercial all-electric vehicles: a review," IEEE Trans. Veh. Technol., vol. 61, no. 2, pp. 475-484, Feb. 2012.

[3] A. Chiba, K. Kiyota, N. Hoshi, M. Takemoto, S. Ogasawara, "Development of a rare-earth-free SR motor with high torque density for hybrid vehicles," IEEE Trans. Energy Convers., vol. 30, no. 1, pp.175-182, Mar. 2015.

[4] K. Kiyota, and A. Chiba, "Design of switched reluctance motor competitive to 60-kW IPMSM in third-generation hybrid electric vehicle," IEEE Trans. Ind. Appl., vol. 48, no. 6, pp. 2303-2309, Nov./Dec. 2012.

[5] S. E. Schulz, and K. M. Rahman, "High-performance digital PI current regulator for EV switched reluctance motor drives," IEEE Trans. Ind. Appl., vol. 39, no. 4, pp. 1118-1126, Jul./Aug. 2003.

[6] Z. Q. Zhu, X. Liu, and P. Zaiping, "Analytical model for predicting maximum reduction levels of vibration and noise in switched reluctance machine by active vibration cancellation," IEEE Trans. Energy Convers., vol. 26, no. 1, pp. 36-45, Mar. 2011.

[7] H. Chen, S. Lu, "Fault diagnosis digital method for power transistors in power converters of switched reluctance motors," IEEE Trans. Ind. Electron., vol. 60, no. 2, pp. 749- 762, Feb. 2013.

[8] T. Ishikawa, Y. Hashimoto, and N. Kurita, "Optimum design of a switched reluctance motor fed by asymmetric bridge converter using experimental design method," IEEE Trans. Magn., vol. 50, no. 2, pp. 781-784, Feb. 2014.

[9] Y. Zou, K. E. Cheng, N. C. Cheung, and J. Pan, "Deformation and noise mitigation for the linear switched reluctance motor with skewed teeth structure,” IEEE Trans. Magn., vol. 50, no. 11, pp. 1-4, Nov. 2014.

[10] R. B. Inderka, and R. W. A. A. De Doncker, "High-dynamic direct average torque control for switched reluctance drives," IEEE Trans. Ind. Appl., vol. 39, no. 4, pp. 1040-1045, Jul./Aug. 2003.

[11] P. O. Rasmussen, J. H. Andreasen, and J. M. Pijanowski, "Structural stator spacers-a solution for noise reduction of switched reluctance motors," IEEE Trans. Ind. Appl., vol. 40, no. 2, pp. 574-581, Mar./Apr. 2004.

[12] Y. Hu, X. Song, W. Cao, and B. Ji, "New SR drive with integrated charging capacity for plug-in hybrid electric vehicles (PHEVs)" IEEE Trans. Ind. Electron., vol. 61, no. 10, pp. 5722- 5731, Oct. 2014.

[13] M. Budhia, J. T. Boys, G. A. Covic, C.U. Huang, "Development of a single-sided flux magnetic coupler for electric vehicle IPT charging systems," IEEE Trans. Ind. Electron., vol. 60, no. 1, pp. 318-328, Jan. 2013.

[14] A. Khaligh, S. Dusmez, "Comprehensive topological analysis of conductive and inductive charging solutions for plug-in electric vehicles," IEEE Trans. Veh. Technol., vol. 61, no. 8, pp. 3475-3489, Oct. 2012.

[15] C. J. Shin, J. Y. Lee, "An electrolytic capacitor-less bi-directional EV on-board charger using harmonic modulation technique," IEEE Trans. Power Electron., vol. 29, no. 10, pp. 5195-5203, Oct. 2013.

[16] J. Hong, H. Lee, K. Nam, "Charging method for the secondary battery in dual-inverter drive Systems for electric vehicles," IEEE Trans. Power Electron., vol. 30, no. 2, pp. 909-921, Feb. 2015.

[17] B. Whitaker, A. Barkley, Z. Cole, B. Passmore, D. Martin, T. R. McNutt, A. B. Lostetter, J. S. Lee, K. Shiozaki, "A high-density, high-efficiency, isolated on-board vehicle battery charger utilizing silicon carbide power devices,” IEEE Trans. Power Electron., vol. 29, no. 5, pp. 2606-2617, May. 2013.

[18] M. Yilmaz, P. T. Krein, "Review of battery charger topologies, charging power levels, and infrastructure for plug-in electric and hybrid vehicles," IEEE Trans. Power Electron., vol. 28, no. 5, pp.2151-2169, May 2013.

[19] W. Y. Choi, M. K. Yang, and H. S. Cho, "High-frequency-link soft-switching PWM DC-DC converter for EV on-board battery chargers," IEEE Trans. Power Electron., vol. 29, no. 8, pp. 4136-4145, Aug. 2014.
[20] S. Y. R. Hui, W. W. C. Ho, "A new generation of universal contactless battery charging platform for portable consumer electronic equipment," IEEE Trans. Power Electron., vol. 20, no. 3, pp.620-627, May 2005.

[21] C. Aguilar, F. Canales, J. Arau, J. Sebastian, J. Uceda, "An integrated battery charger/discharger with power-factor correction," IEEE Trans. Ind. Electron., vol. 44, no. 5, pp. 597-603, Oct. 1997.

[22] Y. J. Lee, A. Khaligh, A. Emadi, "Advanced integrated bidirectional AC/DC and DC/DC converter for plug-in hybrid electric vehicles," IEEE Trans. Veh. Technol., vol. 58, no. 8, pp. 3970-3980, Oct. 2009.

[23] S. Haghbin, K. Khan, S. Zhao, M. Alakula, S. Lundmark, O. Carlson, "An integrated 20-kW motor drive and isolated battery charger for plug-in vehicles," IEEE Trans. Power Electron., vol. 28, no. 8, pp. 4013-4029, Aug. 2013.

[24] H. C. Chang, C. M. Liaw, "Development of a compact switched-reluctance motor drive for EV propulsion with voltage-boosting and PFC charging capabilities," IEEE Trans. Veh. Technol., vol. 58, no. 7, pp. 3198-3215, Sep. 2009.

[25] H. C. Chang,; C. M. Liaw, "An integrated driving/charging switched reluctance motor drive using three-phase power module," IEEE Trans. Ind. Electron., vol. 58, no. 5, pp. 1763-1775, May 2011.

[26] S. Haghbin, S. Lundmark, M. Alaküla, and O. Carlson, "An isolated high-power integrated charger in electrified-vehicle applications," IEEE Trans. Veh. Technol., vol. 60, no. 9, pp. 4115-4126, Nov. 2011.

[27] L. De Sousa, H. Dogan, "Method of evaluating the zero-sequence inductance ratio for electrical machines," the 14th European Conference on Power Electronics and Applications (EPE 2011), pp.1-10, 2011.

[28] K. M. Yoo, K. D. Kim, and J. Y. Lee, "Single- and three-phase PHEV onboard battery charger using small link capacitor," IEEE Trans. Ind. Electron., vol. 60, no. 8, pp. 1763-1775, May 2013.

[29] J. Y. Lee, "An EL capacitorless EV on-board charger using harmonic modulation technique," IEEE Trans. Ind. Electron., vol. 61, no. 4, pp.1784-1787, May 2014.

[30] H. Wang, S. Dusmez, and A. Khaligh, "Maximum efficiency point tracking technique for LLC based PEV chargers through variable DC link control," IEEE Trans. Ind. Electron., vol. 61, no. 11, pp. 6041-6049, May 2014.

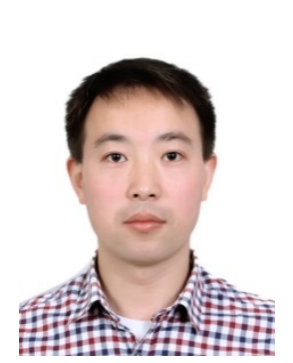

Yihua Hu (M'13) received the B.S. degree in electrical motor drives in 2003, and the Ph.D. degree in power electronics and drives in 2011, both from China University of Mining and Technology, Jiangsu, China. Between 2011 and 2013, he was with the College of Electrical Engineering, Zhejiang University as a Postdoctoral Fellow. Between November 2012 and February 2013, he was an academic visiting scholar with the School of Electrical and Electronic Engineering, Newcastle University, Newcastle upon Tyne, UK. He is currently a research associate with the Department of Electronic \& Electrical Engineering, University of Strathclyde, Glasgow, UK. He has published more than 50 technical papers in leading journals and conference proceedings. His research interests include PV generation system, power electronics converters \& control, and electrical motor drives.

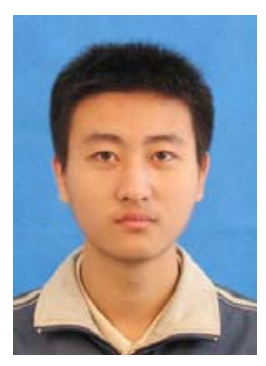

Chun Gan (S'14) received B.S. and M.S. degrees in power electronics and drives from China University of Mining and Technology, Jiangsu, China, in 2009 and 2012, respectively. He is currently working toward Ph.D. degree in the College of Electrical Engineering, Zhejiang University, Hangzhou, China.

His research interests include electrical motor drives, motor design, control with emphasis on switched reluctance motor sensorless technique, and optimization of the torque ripple and efficiency of the motor system. 
IEEE TRANSACTIONS ON INDUSTRIAL ELECTRONICS

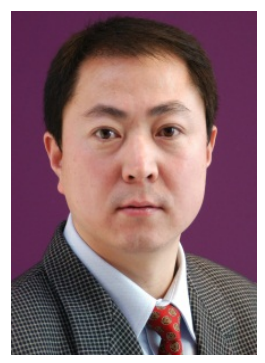

Wenping Cao (M'05-SM'11) received the B.Eng. degree in electrical engineering from Beijing Jiaotong University, Beijing, China, in 1991, and the Ph.D. degree in electrical machines and drives from the University of Nottingham, Nottingham, U.K., in 2004. $\mathrm{He}$ is currently a Marie Curie Fellow with the Massachusetts Institute of Technology, Cambridge, MA, USA, and a Senior Lecturer with Queen's University Belfast, Belfast, U.K. His research interests are in fault analysis and condition monitoring of electric machines and power electronics. Dr. Cao received the Best Paper Award at the Linear Drives for Industry Applications (LDIA'13) Conference, the Innovator of the Year Award from Newcastle University, in 2013, and was the Winner of the Dragons' Den Competition at Queen's University Belfast, in 2014. He is also a Member of the Institution of Engineering and Technology, and a Fellow of the Higher Education Academy. He serves as an Associate Editor for IEEE TRANSACTIONS ON INDUSTRY APPLICATIONS, IEEE INDUSTRY APPLICATIONS MAGAZINE, and IET Power Electronics; the Chief Editor for two special issues; and an Edi- tor/Associate Editor for nine other international journals.

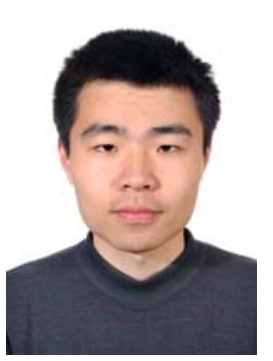

Chushan Li (S'10-M'15) received the B.E.E. degree from the Department of Electrical Engineering, Zhejiang University, China, in 2008. He received the Ph.D. degree from the College of Electrical Engineering, Zhejiang University, China, in 2014. The major is Power Electronics. From December 2013 to June 2014, he was a postdoctoral fellow in Hong Kong Polytechnic University. He is current a postdoctoral research fellow in Ryerson University, Canada, since July 2014.

From April to September in 2008, he was an internship student with the Power Application Design Center in National Semiconductor (Hong Kong) Co.Ltd. From December 2010 to October 2011, he was a visiting scholar with the Freedm Center in North Carolina State University, where he worked on the researches of solid state transformer and smart grid. His research interest includes renewable energy technology, direct AC-AC power conversion and high power density AC-DC converter design.

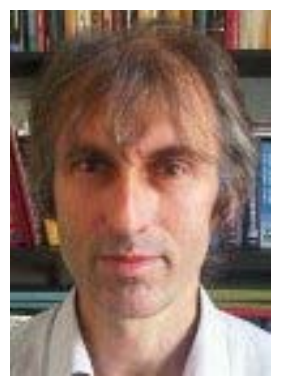

Stephen J. Finney received the M.Eng. degree from Loughborough University of Technology, Loughborough, U.K., in 1988 and the Ph.D. degree from Heriot-Watt University, Edinburgh, U.K., in 1995.For two years, he was with the Electricity Council Research Centre laboratories near Chester, U.K. He is currently a Professor with the University of Strathclyde, Glasgow, U.K. His areas of research interest are HVDC, MMC, renewable generation, and electrical vehicle. 